This item was submitted to Loughborough's Research Repository by the author.

Items in Figshare are protected by copyright, with all rights reserved, unless otherwise indicated.

\title{
Laser micro-nano texturing of a polycrystalline ultra-hard cutting tool to improve wear behaviour
}

\section{PLEASE CITE THE PUBLISHED VERSION}

https://doi.org/10.1117/12.2507208

PUBLISHER

(c) SPIE

VERSION

VoR (Version of Record)

LICENCE

CC BY-NC-ND 4.0

\section{REPOSITORY RECORD}

Pacella, Manuela, Amir Badiee, and Priyanka Ghosh. 2019. "Laser Micro-nano Texturing of a Polycrystalline Ultra-hard Cutting Tool to Improve Wear Behaviour”. figshare. https://hdl.handle.net/2134/37239. 


\section{Laser micro-nano texturing of a polycrystalline ultra-hard cutting tool to improve wear behaviour}

Manuela Pacella, Amir Badiee, Priyanka Ghosh

Manuela Pacella, Amir Badiee, Priyanka Ghosh, "Laser micro-nano texturing of a polycrystalline ultra-hard cutting tool to improve wear behaviour," Proc. SPIE 10906, Laser-based Micro- and Nanoprocessing XIII, 1090607 (4 March 2019); doi: 10.1117/12.2507208

SPIE. Event: SPIE LASE, 2019, San Francisco, California, United States 


\title{
Laser micro-nano texturing of a polycrystalline ultra-hard cutting tool to improve wear behaviour
}

\author{
Manuela Pacella*a, Amir Badiee ${ }^{\mathrm{b}}$, Priyanka Ghosh ${ }^{\mathrm{a}}$ \\ ${ }^{a}$ Wolfson School of Mechanical, Electrical and Manufacturing Engineering, Loughborough

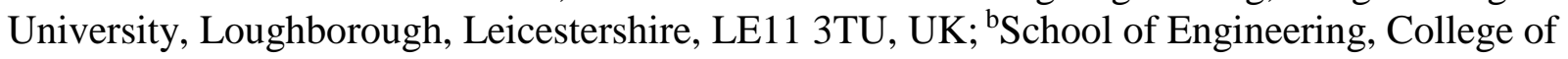 \\ Science, University of Lincoln, Lincolnshire, LN6 7TS, UK
}

\begin{abstract}
Polycrystalline diamond cutting tools are widely used for drilling and turning applications due to their high wear resistance and long durability, however the issue of adhesion of workpiece to the cutting tool significantly affects the cutting tool lifetime. Using a nanosecond fibre laser surface texturing of polycrystalline diamond single point cutting tools is proposed to improve diamond wear and anti-adhesion properties in machining aluminium alloys. The textures, with topographical features' depths and pitch ranging from tens of nanometers to tens of micrometers, were first milled using a fibre laser (1064-nm wavelength) at different fluences, feed speeds and pulse durations, and finally characterised using a combination of Scanning Electron Microscopy, White Light Interferometry and Energy Dispersive X-Ray (EDX). The effect of different textures on the wear properties was investigated in turning tests under dry conditions. The tests were stopped every 20 passes and the wear analysed through an Alicona optical 3D measurements. The online monitoring and post-processing of the cutting forces and the microscopical characterisation of the tested cutting tools allowed the evaluation of the effects of texture design and adhesive properties. For textures depths in the order of $260 \mathrm{~nm}$ and post process roughness in the order of tens of nanometers, a reduction of cutting force and an improvement of antiadhesive effect were achieved in dry turning.
\end{abstract}

Keywords: Polycrystalline diamond insert, cutting tool, laser surface texturing, nanosecond laser, laser milling, adhesion

\section{INTRODUCTION}

Aluminium alloys are the most significantly used alloy for the manufacture of aerospace, automotive and marine equipment. In the precision machining of these alloys, due to their low melting point and high ductility, aluminium chips adhere strongly to the tool cutting edge, causing early tool breakage. Cutting tools made of polycrystalline diamond (PCD) and chemical vapour deposited (CVD) diamond enable an increase in material removal rate and improved surface integrity [1], representing an effective solution to premature failure typical of tungsten carbide tools. Although the low friction coefficient, low chemical affinity, high thermal conductivity and high temperature inertness of diamond make them suitable for precision machining of aluminium alloys [2], the major part of machining still occur in lubricated conditions, contributing to environmental pollution.

To resolve this problem researchers investigated the performance of dry machining of aluminium alloys. Unfortunately, machining efficiency in dry cutting via PCD cutting tools was found to be extremely low and often the occurrence of premature tool failure limits the application of PCD commercially [3]. This is due to higher friction, elevated adhesion on the tool-chip interface, and increased tool wear resulting in reduced tool life.

Recent research proposed functionalization of tool surfaces for improving the wear resistance and to reduce the adhesion of workpiece material to the cutting tool. Xing et al. [4] investigated the effects of surface texturing in various shapes and sizes to improve friction, anti-adhesive properties and wear behaviour in cemented carbide cutting tools. They discovered that microgrooves on the rake face of a cutting tool were effective in reducing cutting forces, which in turn improved the frictional behaviour at the chip-tool interface. They also found that the cutting forces increased proportionally to the groove width when this was in the range 70-200 $\mu \mathrm{m}$.

Manufacturing of periodical micro/nano surface textures on the tool rake face by laser, electrical discharge machining, micro grinding, mechanical machining, and chemical etching was reported [5], [6]. Among the available manufacturing techniques for micro texturing, short pulsed laser micro-machining enabled to generate precise microfeatures and alter the surface morphology of ultrahard cutting tool materials without showing significant surface damage [6]. 
Sugihara and Enomoto [7] fabricated precise regular nano/micro grooves of depth 100- $150 \mathrm{~nm}$ and track distance of 700 $\mathrm{nm}$ on the rake face of a cemented carbide cutting tool using a femto-second laser at a peak wavelength of $800 \mathrm{~nm}$. From scanning electron microscopy (SEM) and energy dispersive X- ray spectrometry (EDX), they found that the nano/micro texture parallel to the main cutting edge improved anti-adhesion, but not satisfactorily on the cutting tool surface. Although it was confirmed that regular nano/micro grooves were not buried by adhesion at a cutting length of $1800 \mathrm{~m}$, a slight adhesion was observed. SEM and EDX results also demonstrated that adhesion would worsen at increased length of cut possibly leading to tool breakage. Later they developed a cutting tool with banded nano/micro groove on the polished tool surface in a direction parallel to the main cutting edge in bands with $50 \mu \mathrm{m}$ width and 100-200 nm depth. They concluded that the newly proposed cutting tool improved anti-adhesive effects and lubricity of the cutting tool. Sugihara and Enomoto [8] later developed a cutting tool with micro stripe textured surface, namely grooves parallel to main cutting edge and grooves orthogonal to the main cutting edge to ensure anti-adhesive properties both in dry and wet cutting conditions. Their experimental results showed that the micro stripe textured surface improved the anti-adhesive properties and cutting performances in dry cutting.

Deng et al. [9] used laser machining for surface texturing on the rake face close to the main cutting edge of WC/Ti/Co carbide tools. They found that the nanoscale surface textures with/without $\mathrm{WS}_{2}$ solid lubricant coatings could significantly reduce the cutting forces, the cutting temperatures, and the tool-chip interface frictional coefficient. They also concluded that the rake face textured tools and the rake face textured tools developed with $\mathrm{WS}_{2}$ coatings had the best cutting performance. Ma et al. [10] numerically investigated the performance of microgroove textured cutting tools designed on the rake face of cemented carbide in dry 3D turning of Ti alloys. They summarized that the microgrooves at $50 \mu \mathrm{m}$ wide of a cutting tool were effective in reducing cutting forces, which improved the frictional behaviour at the chip-tool interface. The results showed that, at $50 \mu \mathrm{m}$ width, the cutting force components were less than those of the regular tool, but all forces became larger than those of the regular tool when the microgroove width increased further from 90 to $120 \mu \mathrm{m}$.

In the need of reducing lubricant pollution to respond to environmental legislations, the objective of this paper is twofold: using a pulsed ytterbium-doped fibre laser (1,064-nm wavelength, $60 \mathrm{~W}$ maximum output power) an experimental study is proposed to investigate the effect of programmable parameters and energetic conditions in microtexturing PCD turning inserts. Secondly, different laser designs are manufactured on PCD inserts to investigate the effect of texturing angle on the machinability and anti-adhesive properties of Al alloys.

\section{METHODOLOGY}

\subsection{Materials}

Commercially available PCD cutting tool inserts in shape SPGN090308F (0.5 mm diamond layer) directly synthetized on a tungsten carbide substrate $(1.1 \mathrm{~mm})$ were selected for this study. The PCD used in the experiments is a composite with average diamond grain size of $10 \mu \mathrm{m}$ infiltrated by cobalt as metallic binder (Co binder volume circa 10.3\%) supplied by Element Six Ltd.

Al Alloy 6082 cylinders $(80 \mathrm{~mm}$ diameter and length $150 \mathrm{~mm}$ ) were used as workpiece material for precision turning.

\subsection{Laser micro-nano processing}

A $70 \mathrm{~W}$ Innolas MMS single mode SPI fibre laser (1060 nm wavelength) was used to process the samples. The computer numerically controlled $(\mathrm{CNC})$ laser machine was operated in pulse mode and delivered pulses based on direct modulation of the seed laser allowing programmed waveforms. The waveforms are the results of an optimization of the peak power at a specific pulse repetition rate. At the waveform considered for the experiments the repetition rate for optimised peak power was $70 \mathrm{kHz}$, the pulse duration was $12 \mathrm{~ns}$; and the maximum pulse energy was $0.17 \mathrm{~mJ}$. Beam diameter at the focal points was measured to be approximately $30 \mu \mathrm{m}$. The laser parameters selected to perform laser processing of the PCD tools were: feed speed of $900 \mathrm{~mm} \mathrm{~s}^{-1}$, intensity of $20 \%$, fluence of $3.38 \mathrm{Jcm}^{-2}$ and frequency of 70 $\mathrm{kHz}$. The grooves were $261 \mathrm{~nm}$ in depth, $7 \mu \mathrm{m}$ in width and spaced at a pitch (centre to centre) of $50 \mu \mathrm{m}$. Three different texture design on the surface of the tool namely grooves perpendicular to the chip flow direction (CFD), grooves parallel 
to CFD (at an acute angle inclined to the direction of the chip flow), and grooves parallel to the main cutting edge (MCE) and the performance of these were benchmarked to a non-textured plain cutting tool.

\subsection{Characterisation method}

All test specimens were placed in a methanol-filled glass vial and cleaned in a water-filled ultrasonic bath for 30 minutes after laser processing to remove any debris or deposition due to the process. A JEOL Zeiss SEM was used to perform imaging and chemical composition using energy dispersive X-ray spectroscopy (EDX). Images were taken of the asreceived and laser processed inserts. The mapping feature was used to determine any changes in chemical composition due to the different processes. A 3D white light interferometer (Alicona InfiniteFocus) was used with a vertical resolution of $110 \mathrm{~nm}$ and lateral resolution of $2.13 \mu \mathrm{m}$. This allowed the topographical analysis of the laser processed and benchmark inserts before and after testing. Each sample was scanned, and three single profiles were extracted from top, bottom and centre of each area. For each sample, 2D roughness parameters namely $\mathrm{Ra}, \mathrm{Rz}$, Rq were extrapolated based on ISO 13565.

\subsection{Testing}

A three-axis machining centre (Haas TL-1 CNC lathe; max. spindle speed 1,800 rpm; spindle power 30kW) was used for the turning tests and the cutting forces were acquired at a sampling rate of $10 \mathrm{kHz}$. A dedicated fixturing system was manufactured to accommodate a three-axis dynamometer (Kistler Kiag Swiss 9257A) connected to three (one for each axis) charge amplifiers (Kistler 5015) and then to a data acquisition board (Picoscope PC Oscilloscope) and dedicated Picoscope application to save and process the signals. Monitored cutting forces and their respective directions are shown in Figure 1. A commercial tool holder with rake angle of $8^{\circ}$ was used to hold the inserts. A depth of cut of $1 \mathrm{~mm}$, feed rate of $0.1 \mathrm{~mm} / \mathrm{rev}$, cutting speed of $250 \mathrm{~m} / \mathrm{min}$ and length of cut of $100 \mathrm{~mm}$ were used to perform the longitudinal cutting trials on Al Alloy 6082 under dry conditions.

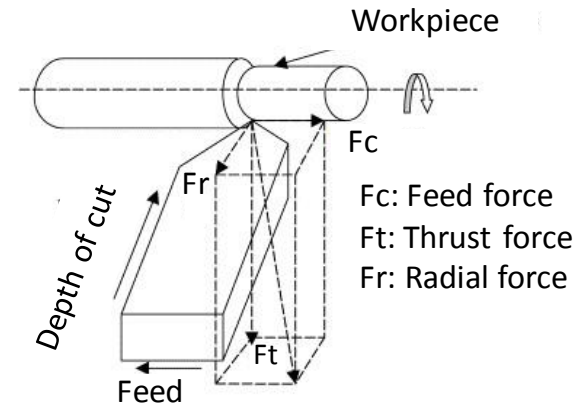

Figure 1. Schematic illustration of the cutting forces.

\section{RESULTS AND DISCUSSION}

\subsection{Laser micro-nano manufacturing and characterisation}

Feed speed variation showed to affect the achieved surface roughness in accordance with previous research [11] where it was found that at slower processing conditions $\left(70 \mathrm{mms}^{-1}\right)$ the PCD material has longer exposure time to absorb the laser irradiation. This would result in absorption of the laser energy, conversion into thermal energy, and transformation of metastable diamond into stable graphite while the melting Cobalt would expand producing compressive stresses on diamond grains. In this work, the selected speed $\left(900 \mathrm{mms}^{-1}\right)$ allowed to decrease the energy absorption and conversion and avoid the formation of residual stresses typical of polycrystalline diamond (Co binder volume circa 10.3\%). Optimisation of the necessary laser intensity to achieve features in the order of $200 \mathrm{~nm}$ was carried out and Figure 2 depicts the results achieved through nanosecond laser processing at $20 \%$ laser intensity (70W maximum output power). 
For the considered PCD material a low-energy ablation is the necessary manufacturing process to achieve repeatable nano-scale grooves. The optimised laser fluence $\left(3.38 \mathrm{~J} \mathrm{~cm}^{-2}\right)$ on the target caused a milling mechanism typical of PCD material below its ablation threshold, thus the resulting mechanism is purely thermal on Cobalt, and purely mechanical on the crystallites: higher grain-to-grain bonding forces prevent milling. This was explained by Pacella et al. for a higher binder content PCD material [11].

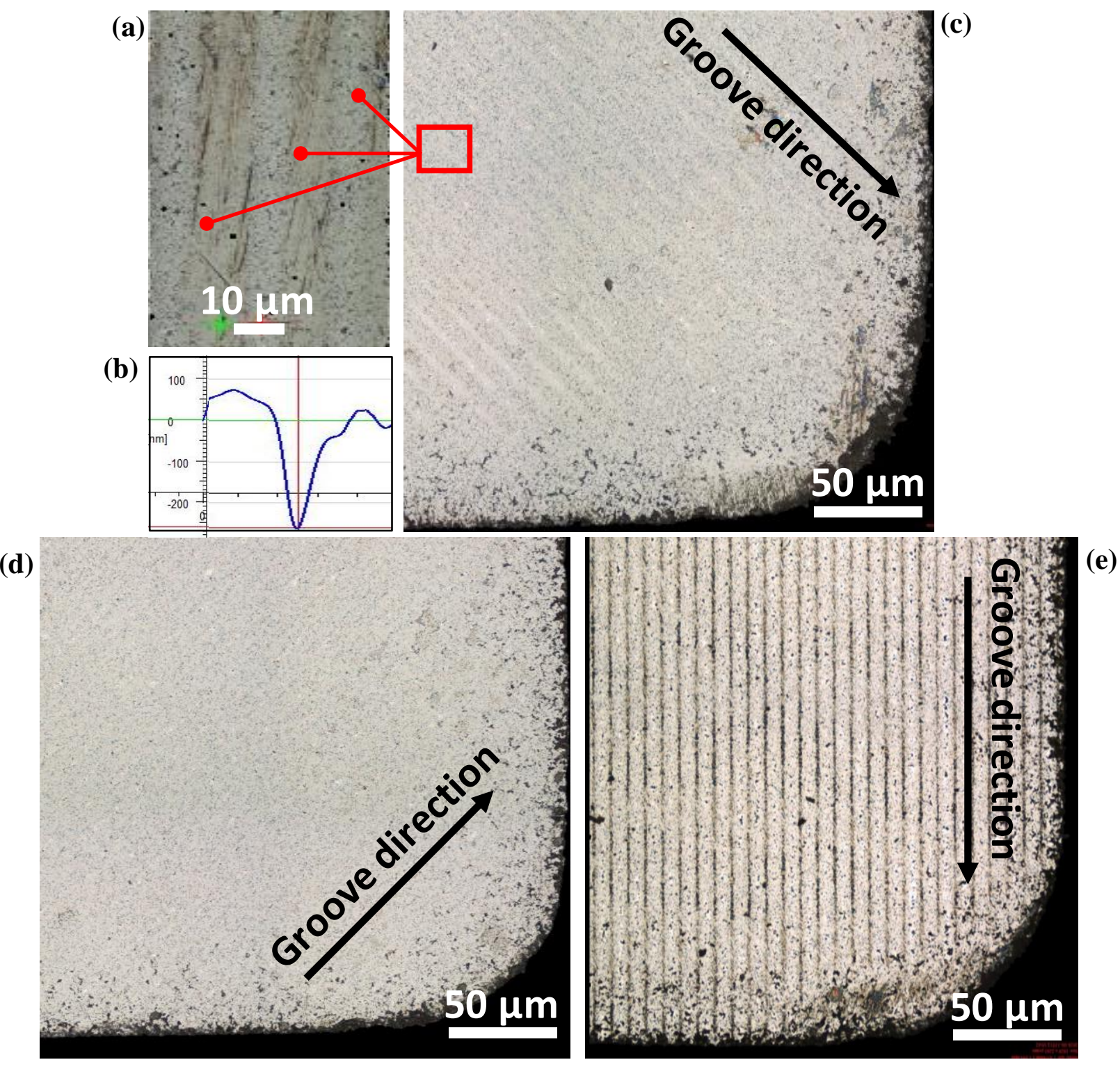

Figure 2. Micro-nano laser processed samples: a) optical microscopy in top view of the grooves, b) surface roughness profile of a single groove in cross section; c) optical microscopy of grooves parallel to CFD, (d) grooves perpendicular to CFD, and (e) grooves parallel to main cutting edge.

\subsection{Turning test}

Results of turning test revealed the benchmark tool and the insert with grooving parallel to the main cutting edge to be prone to chipping with chips above $50 \mu \mathrm{m}$ for the benchmark (Figure 3a) and below $40 \mu \mathrm{m}$ for the lasered inserts (Figure $3 d)$. 
The remaining laser processed tools showed a different wear mechanism substantiated by the presence of an important crater wear. This was circa $50 \mu \mathrm{m}$ in length for the grooves parallel to the chip flow direction (Figure $3 \mathrm{~b}$ ) and circa 80 $\mu \mathrm{m}$ in the case of grooves perpendicular to the chip flow direction (Figure 3c). This can be explained considering the trajectory of the Al alloy chip formed while cutting. Based on previous research [8], it is expected that grooves parallel to the chip flow direction would promote chip escape through the grooves, however the experiments carried out in this paper revealed that the mechanism for chip formation and chip flow would depend on the chip thickness and aspect ratio of the grooves.
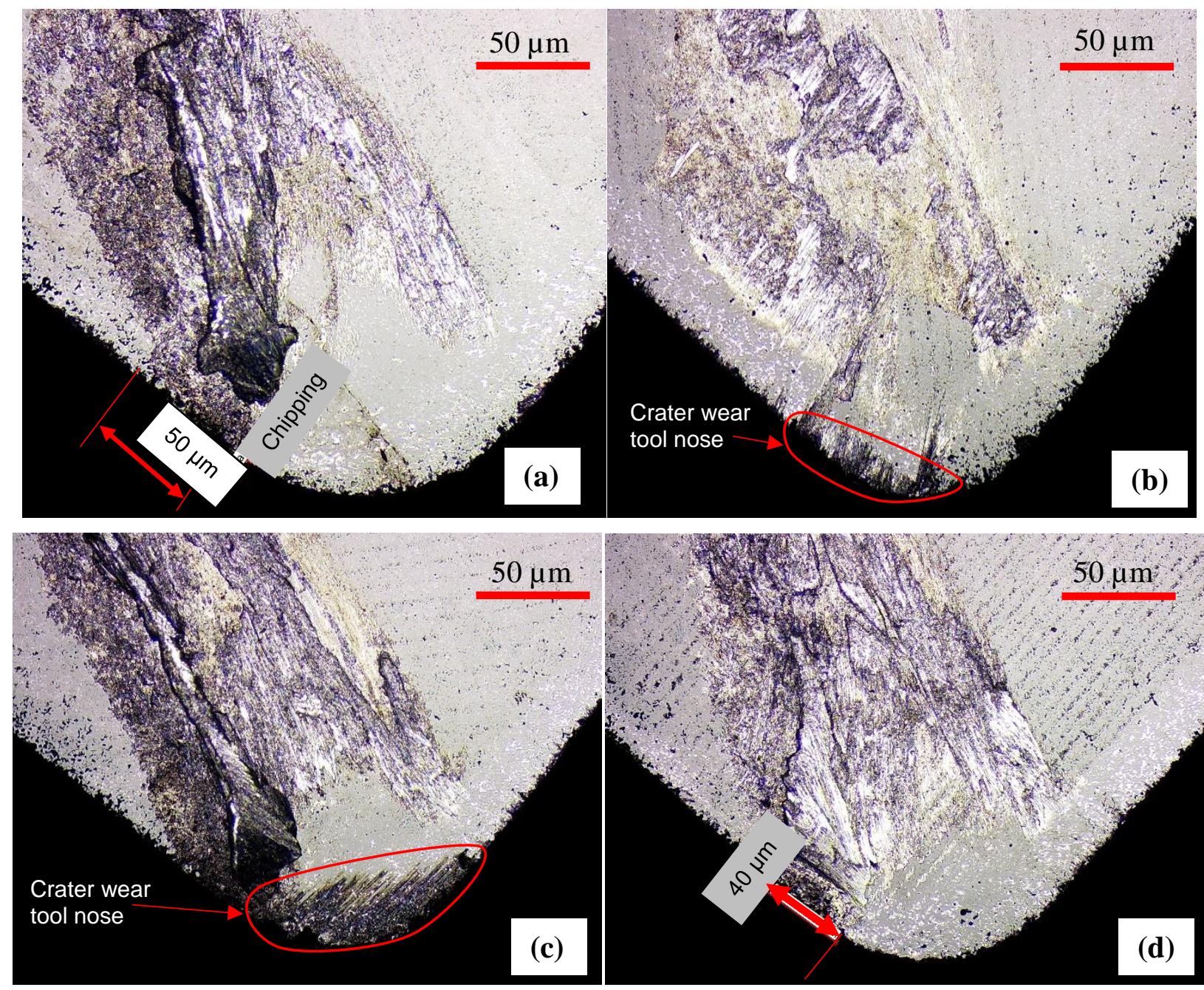

Figure 3. Optical microscopy images of wear marks on the rake face and the tool nose of PCD tools after $2758 \mathrm{~m}$ : (a) benchmark, (b) grooves parallel to CFD, (c) grooves perpendicular to CFD, and (d) grooves parallel to MCE.

During turning tests monitoring of feed, thrust and radial forces showed a homogeneous trend for each of the tested samples. An example of the average thrust force captured at $873 \mathrm{~m}$ showing the influence of different micro-grooved PCD tools and the benchmark is depicted in Figure 4. The reduction of average thrust force seems to indicate that the tool with grooves perpendicular to CFD and grooves parallel to MCE performed superiorly as opposed to conventional cutting whilst the forces for the tool with grooves parallel to CFD machining cases showed intermittent variations (higher forces). Compared with the benchmark, low radial force and thrust force can be achieved with micro-textured PCD tools under dry cutting conditions. All lasered inserts revealed a reduction of average cutting forces, however, insert with grooves parallel to chip flow direction showed a high scatter of forces as evidenced by the lower and upper quartiles in the box plot in Figure 4. 


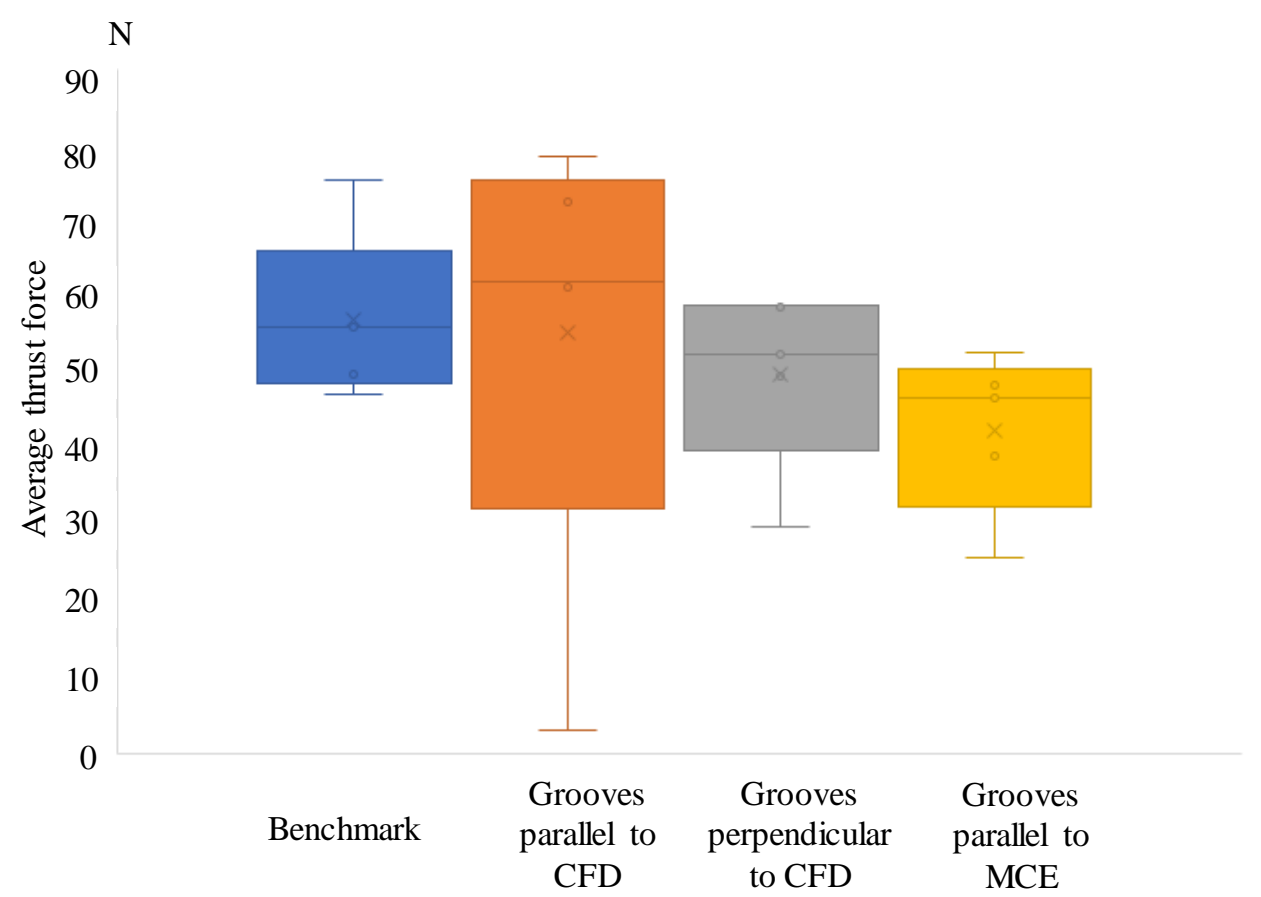

Figure 4. Comparison in average thrust force for benchmark and processed inserts at a cutting length of $873 \mathrm{~m}$.

\subsection{Energy-dispersive X-ray spectroscopy for adhesion analysis}

White light interferometry results (Figure 5) allowed a quantitative analysis of the depth and direction of the adhered Aluminium on the rake face of the inserts. On the tool rake face of the benchmark tool (Figure 5a) and insert with grooves perpendicular to CFD (Figure 5b), a high degree of swarf is evident in the chip flow direction.

Figure $5 \mathrm{~b}$ shows the stiction of the aluminium on the insert with grooves parallel to CFD cutting at a length of cut of $2758 \mathrm{~m}$. In this case the degree of adhesion $(50 \mu \mathrm{m})$ was observed to be significantly lower than for the benchmark (asreceived) tool, which was measured at $90 \mu \mathrm{m}$ (Figure 5a). This observation suggests that regardless of the direction of grooves provided, the provision of nanogrooves on the rake face resulted in reduced adhesion of the material on the rake face of the cutting tool.

Overall it appears that the degree of adhesion of the cutting chips to the rake faces reduced significantly (almost half in magnitude) compared to standard cutting by benchmark cutting tool without grooves. 

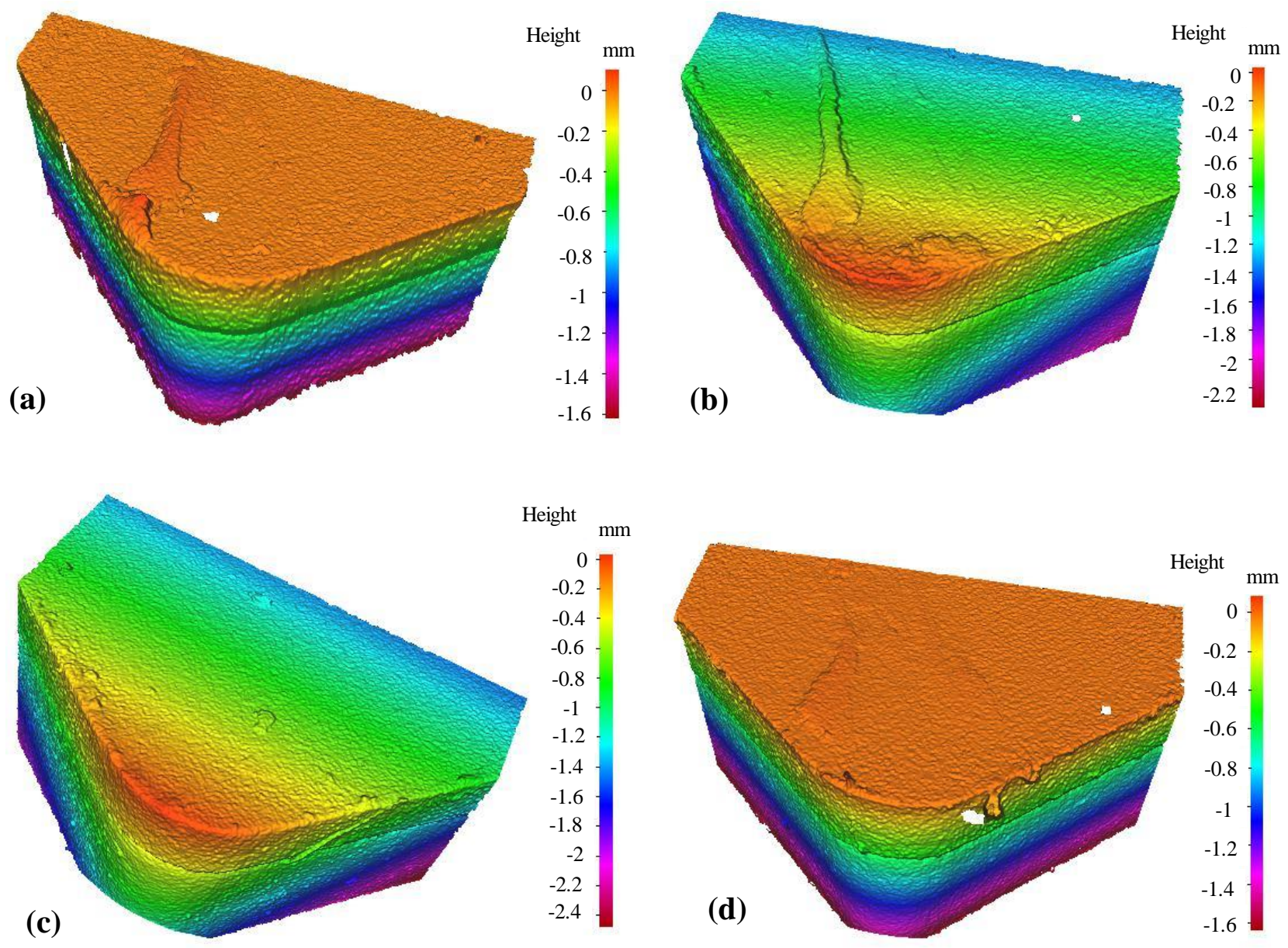

Figure 5. Alicona topographical profiles of wear marks after $2758 \mathrm{~m}$ cutting length of PCD tools: (a) benchmark, (b) grooves perpendicular to $\mathrm{CFD}$, (c) grooves parallel to CFD, and (d) grooves parallel to main cutting edge.

Based on the EDX assessment, mainly, Carbon (C) and Aluminium (Al) and Tungsten (W) were detected to be present on the rake face of the cutting tool after machining. The presence of aluminium is purely due to the material transfer during machining in the form of built up edge (BUE).

Figure 6a highlights the incipient wear of the PCD tool on the flank face with heavy sites of aluminium stiction on the surface which was also confirmed by microscopical analysis. Heavy adhesion of aluminium in form of built up edge was also revealed by EDX/SEM analysis. Figure 6d shows results from EDX analysis on the material stiction on the cutting tool with grooves parallel to the main cutting edge.

EDX results for the flank face of the benchmark (Figure 6a), grooves perpendicular to CFD (Figure 6b) and grooves parallel to main cutting edge (Figure 6d) showed a high degree of Aluminium adhesion. This result is in accordance with previous research [8] which revealed that nano/micro-texture on the cutting tool surface increased adhesion of aluminium chips to the surface in dry cutting. This may be caused by the cutting stresses and high temperature which can promote shear induced flow of workpiece material in the cutting zone leading to the formation and flow of the cutting chips from the aluminium alloy.

In this study, however, it was revealed that lasering of grooves in the direction parallel to chip flow drastically reduced the aluminium stiction compared to both benchmark tool and other lasered ones. This is caused by two phenomena. Being the features parallel to the chip flow, the tool-chip contact area is reduced, and this resulted in a decrease of temperature which promoted the chip to flow faster and reduced plugging of the textures (Figure 6c) limiting the microgrooves to act as a micro-trap for wear debris. Furthermore, there is a shift in the wear mechanism likely caused by the groove direction and the manufacturing technique utilised. 

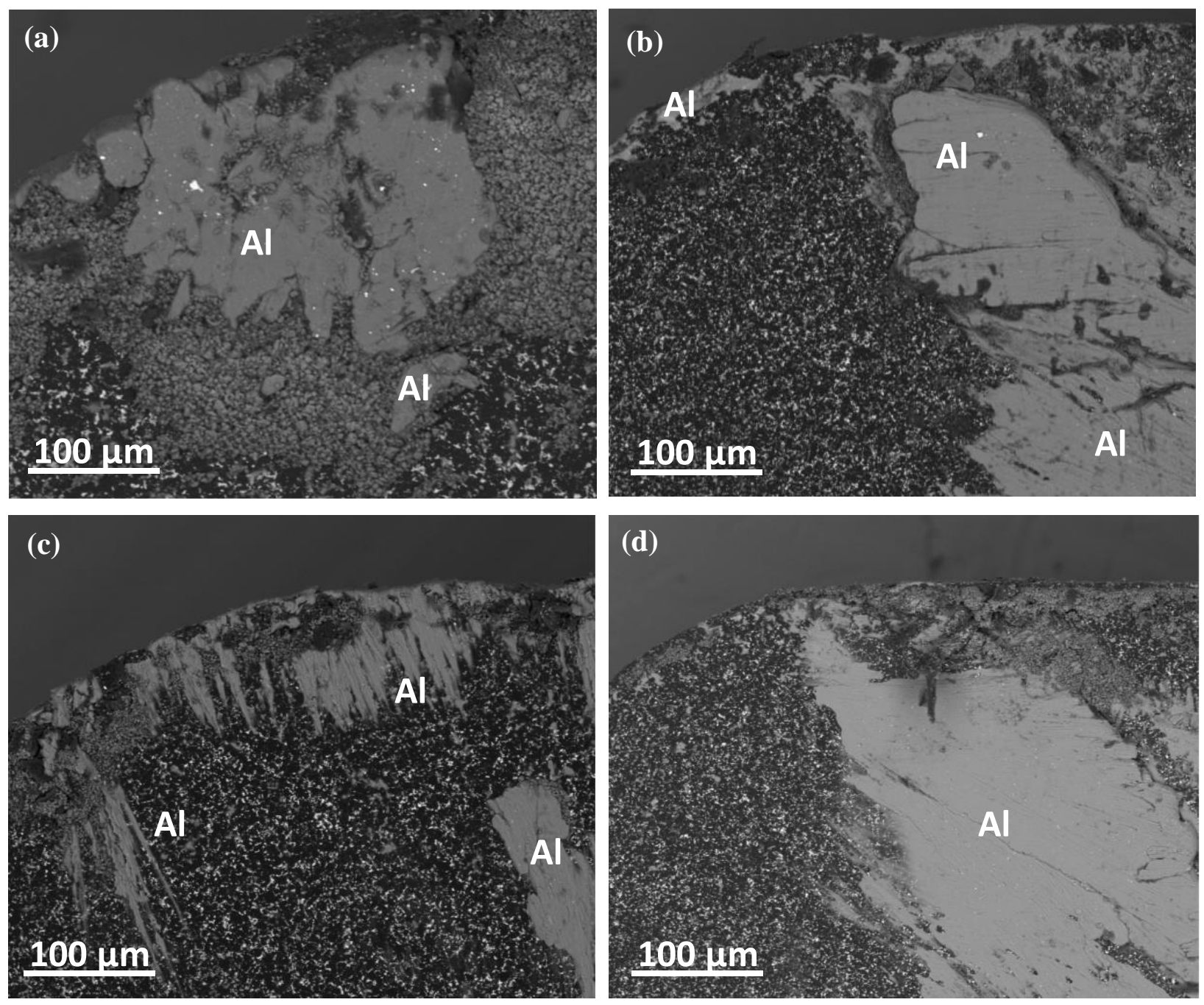

Figure 6. Scanning electron microscopy (top view) and EDX chemical analysis of the PCD tools at 2758 m: (a) benchmark, (b) grooves perpendicular to CFD, (c) grooves parallel to CFD and (d) grooves parallel to MCE.

\section{CONCLUSIONS}

An optimised laser manufacturing process has enabled to manufacture micro-nano grooves on the tip of a PCD composite cutting tool to improve wear behaviour in the machining of Aluminium alloys.

For textures depths in the order of $260 \mathrm{~nm}$ and post process roughness in the order of tens of nanometers, a reduction of cutting force and an improvement of anti-adhesive effect were achieved in dry turning using an insert with grooves parallel to the chip flow direction. Condition monitoring of thrust, feed and radial forces showed a reduction of average cutting forces for all lasered inserts when compared to the benchmark.

The combination of white light interferometry with EDX/SEM analysis allowed a quantitative identification of the stiction of aluminium to the cutting tool for the four different inserts. It was revealed that lasering of grooves in the direction parallel to the chip flow drastically reduced the aluminium stiction compared to both benchmark tool and all the other lasered inserts. This was caused by a reduction of the tool-chip contact area which resulted in a decrease of temperature which enabled the micro-grooves to act as a micro-trap for wear debris avoiding build-up edge. The formation of a not negligible crater wear seems to reveal that it is possible to change the wear mechanism via lasering of features engineered to reduce workpiece adhesion to the cutting tool. 


\section{ACKNOWLEDGMENT}

The authors would like to acknowledge the financial support granted by the Institution of Mechanical Engineers (IMechE) under travel prize EAC/KDF/OFFER/18/100 and the support of Element Six Ltd. for providing the polycrystalline diamond materials.

\section{REFERENCES}

[1] Fraga da Silva, T., Soares, R. B., Jesus, A. M. P., Rosa, P. A. R. and Reis, A., "Simulation studies of turning of aliminium cast alloy using PCD tools," Procedia CIRP 58, 555-560 (2017).

[2] Kalyan, C. and Samuel, G. L., "Cutting mode analysis in high speed finish turning of AlMgSi alloy using edge chamfered PCD tools," J. Mater. Process. Technol. 216, 146-159 (2015).

[3] Eberle, G., Dold, C. and Wegener, K., "Laser fabrication of diamond micro-cutting tool-related geometries using a high-numerical aperture micro-scanning system,” Int. J. Adv. Manuf. Technol. 81, 1117-1125 (2015).

[4] Kang, Z., Fu, Y., Ji, J. and Tian, L., "Numerical investigation of microtexture cutting tool on hydrodynamic lubrication," J. Tribol. 139(5), 54502-54510 (2017).

[5] Hu, T., Hu, L. and Ding, Q., "Effective solution for the tribological problems of Ti-6Al-4V: Combination of laser surface texturing and solid lubricant film," Surf. Coatings Technol. 206(24), 5060-5066 (2012).

[6] Pacella, M., Axinte, D. A., Butler-Smith, P. W., Shipway, P., Daine, M. and Wort, C., "An assessment of the wear characteristics of microcutting arrays produced from polycrystalline diamond and cubic boron nitride composites," J.

Manuf. Sci. Eng. 138(2), 21001-210016 (2015).

[7] Sugihara, T. and Enomoto, T., "Development of a cutting tool with a nano/micro-textured surface-Improvement of anti-adhesive effect by considering the texture patterns," Precis. Eng. 33(4), 425-429 (2009).

[8] Sugihara, T. and Enomoto, T., "Improving anti-adhesion in aluminum alloy cutting by micro stripe texture," Precis. Eng. 36(2), 229-237 (2012).

[9] Deng, J., Lian, Y., Wu, Z. and Xing, Y., "Performance of femtosecond laser-textured cutting tools deposited with WS2 solid lubricant coatings," Surf. Coatings Technol. 222, 135-143 (2013).

[10] Ma, J., Duong, N. H. and Lei, S., "3D numerical investigation of the performance of microgroove textured cutting tool in dry machining of Ti-6Al-4V,” Int. J. Adv. Manuf. Technol. 79(5-8), 1313-1323 (2015).

[11] Pacella, M., Nekouie, V. and Badiee, A., "Surface engineering of ultra-hard polycrystalline structures using a nanosecond $\mathrm{Yb}$ fibre laser: Effect of process parameters on microstructure, hardness and surface finish," J. Mater.

Process. Technol. 266, 311-328 (2019). 